\title{
Retrieval of stratospheric ozone profiles from MIPAS/ENVISAT limb emission spectra: a sensitivity study
}

\author{
N. Glatthor ${ }^{1}$, T. von Clarmann ${ }^{1}$, H. Fischer ${ }^{1}$, B. Funke ${ }^{2}$, S. Gil-López ${ }^{2}$, U. Grabowski ${ }^{1}$, M. Höpfner ${ }^{1}$, S. Kellmann ${ }^{1}$, \\ A. Linden ${ }^{1}$, M. López-Puertas ${ }^{2}$, G. Mengistu Tsidu ${ }^{1, *}$, M. Milz ${ }^{1}$, T. Steck ${ }^{1}$, G. P. Stiller ${ }^{1}$, and D.-Y. Wang ${ }^{1, * *}$ \\ ${ }^{1}$ Forschungszentrum Karlsruhe, Institut für Meteorologie und Klimaforschung, Karlsruhe, Germany \\ ${ }^{2}$ Instituto de Astrofísica de Andalucía (CSIC), Granada, Spain \\ *now at: Addis Ababa University, Department of Physics, Addis Ababa, Ethiopia \\ *** now at: University of New Brunswick, Physics Department, Fredericton, NB E3B 5A3, Canada
}

Received: 18 August 2005 - Published in Atmos. Chem. Phys. Discuss.: 23 November 2005

Revised: 4 April 2006 - Accepted: 7 June 2006 - Published: 7 July 2006

\begin{abstract}
We report on the dependence of ozone volume mixing ratio profiles, retrieved from limb emission infrared spectra of the Michelson Interferometer for Passive Atmospheric Sounding (MIPAS), on different retrieval setups such as the treatment of the background continuum, cloud filtering, spectral regions used for analysis and a series of further more technical parameter choices. The purpose of this investigation is to better understand the error sources of the ozone retrieval, to optimize the current retrieval setup and to document changes in the data versions. It was shown that the cloud clearing technique used so far (cloud index 1.8) does not reliably exclude all cloud-contaminated spectra from analysis. Through analysis of spectra calculated for cloudy atmospheres we found that the cloud index should be increased to a value of 3.0 or higher. Further, it was found that assignment of a common background continuum to adjacent microwindows within $5 \mathrm{~cm}^{-1}$ is advantageous, because it sufficiently represents the continuum emission by aerosols, clouds and gases as reported in the literature, and is computationally more efficient. For ozone retrieval we use ozone lines from MIPAS band A $\left(685-970 \mathrm{~cm}^{-1}\right)$ and band AB (1020-1170 $\left.\mathrm{cm}^{-1}\right)$ as well. Therefore we checked ozone retrievals with lines from bands $\mathrm{A}$ or $\mathrm{AB}$ only for a systematic difference. Such a difference was indeed found and could, to a major part, be attributed to the spectroscopic data used in these two bands, and to a minor part to neglection of modelling of non-local thermodynamic (non-LTE) emissions. Another potential explanation, a bias in the radiance calibration of level-1B spectra of bands $A$ and $A B$, could largely be ruled out by correlation analysis and inspection of broadband spectra. Further upgrades in the ozone retrieval consist of application of an all-zero a-priori pro-
\end{abstract}

Correspondence to: N. Glatthor

(norbert.glatthor@imk.fzk.de) file and a weaker regularization. Finally, the ozone distribution obtained with the new retrieval setup (data versions V3o_O3_7) was compared to the data version used before (V2_O3_2). Differences are smaller than $\pm 0.4 \mathrm{ppmv}$ in the altitude region $15-50 \mathrm{~km}$. Further, differences to ozone measured by the HALogen Occultation Experiment (HALOE) on the Upper Atmospheric Research Satellite (UARS) are partly reduced with the new MIPAS data version.

\section{Introduction}

The Michelson Interferometer for Passive Atmospheric Sounding (MIPAS) is a limb-viewing Fourier transform infrared (FTIR) emission spectrometer with an unapodised spectral resolution of $0.035 \mathrm{~cm}^{-1}$ (Fischer and Oelhaf, 1996; European Space Agency (ESA), 2000). It was launched onboard the Sun-synchronous polar-orbiting European ENVIronmental SATellite (ENVISAT) on 1 March 2002. MIPAS covers a wide mid-infrared spectral region, namely from 685 to $2410 \mathrm{~cm}^{-1}$, which enables simultaneous observation of various trace gases. The original standard observation mode, which generally was operated until 26 March 2004, consisted of limb-scans in anti-flight direction, composed of 17 altitude steps with tangent altitudes between 6 and $68 \mathrm{~km}$. The step-width was $3 \mathrm{~km}$ up to $42 \mathrm{~km}$ and increased up to $8 \mathrm{~km}$ above $52 \mathrm{~km}$. Generation of calibrated, so-called level-1B radiance spectra is described in Nett et al. (2002). Several data analysis schemes have been developed for near-real time and off-line retrieval of profiles of atmospheric trace species from calibrated MIPAS spectra provided by the European Space Agency (ESA) (von Clarmann et al., 2003a). The ozone distributions presented in this paper were derived with the retrieval processor of the Institut für Meteorologie und

Published by Copernicus GmbH on behalf of the European Geosciences Union. 
Klimaforschung (IMK), which was developed to produce self-consistent datasets containing considerably more trace species than included in the operational dataset provided under ESA responsibility. At IMK, for retrieval of stratospheric ozone profiles from spectra measured in the standard observation mode local thermodynamic equilibrium (LTE) is assumed, which is valid for most species throughout the troposphere and stratosphere. For analysis of trace species in non-local thermodynamic equilibrium (NLTE), which becomes important for MIPAS observations of the upper atmosphere, the processor capabilities were extended at the Instituto de Astrofísica de Andalucía (IAA).

Retrieval of ozone profiles from limb emission spectra meanwhile is rather routine. However, different retrieval algorithms and setups will produce different ozone profiles from the same set of measurements. This is, to a certain degree, even true for the ideal case of synthetic measurements only perturbed by random noise (von Clarmann et al., 2003a). With real measured spectra, the situation is even worse, because the setup of the retrieval determines how, e.g., uncertainties in spectroscopic data, unaccounted physics such as NLTE emissions, or calibration uncertainties, map onto the retrieved profiles. In this paper we assess the sensitivity of ozone retrievals to the detection scheme for cloud contaminated spectra, to the treatment of background continuum emission, and to the MIPAS bands chosen for retrieval of ozone profiles, i.e. MIPAS band A $\left(685-970 \mathrm{~cm}^{-1}\right)$ or AB $\left(1020-1170 \mathrm{~cm}^{-1}\right)$ only or a combination of both bands. The goal of these investigations is to better understand related retrieval error sources and to optimize the retrieval setup. Further, we compare the results to ozone measured by the HALogen Occultation Experiment (HALOE) and investigate, if the detected discrepancies can be related to the retrieval parameter settings chosen. A possible residual bias to independent experiments is quantified in a comprehensive validation study (Steck et al., 2006) ${ }^{1}$.

\section{Retrieval of vertical ozone profiles}

In the retrievals performed with the IMK-IAA data processor, MIPAS level-1B spectra are inverted to vertical profiles of atmospheric state parameters by constrained non-linear least squares fitting of modeled to measured spectra (e.g., Rodgers, 2000, and references therein) by minimising the objective function

$\chi^{2}=\left(\boldsymbol{y}_{m}-\boldsymbol{y}_{c}\right)^{T} S_{y}^{-1}\left(\boldsymbol{y}_{m}-\boldsymbol{y}_{c}\right)+\left(\boldsymbol{x}_{a}-\boldsymbol{x}\right)^{T} R\left(\boldsymbol{x}_{a}-\boldsymbol{x}\right) .(1)$

${ }^{1}$ Steck, T., Blumenstock, T., von Clarmann, T., Glatthor, N., Grabowski, U., Hase, F., Hochschild, G., Höpfner, M., Kellmann, S., Kiefer, M., Kopp, G., Linden, A., Milz, M., Oelhaf, H., Stiller, G.P., Wetzel, G., Zhang, G., Fischer, H., Funke, B., Wang, D.-Y., von der Gathen, P., Hansen, G., Stebel, K., Kyrö, E., Allaart, M., Redondas Marrero, A., Remsberg, E., Russell III, J., Steinbrecht, W., Yela, M., and Raffalski, U.: Validation of ozone measurements from MIPAS-Envisat, J. Geophys. Res., submitted, 2006.
Here $\boldsymbol{y}_{m}$ and $\boldsymbol{y}_{c}$ are the measured and modelled spectral radiances, $\mathbf{S}_{y}$ is the covariance matrix of measurement noise, $\boldsymbol{x}_{a}$ and $\boldsymbol{x}$ are the a-priori and retrieved profile and $\mathbf{R}$ is the regularization matrix. First, spectral shift, the temperature profile and the tangent heights are fitted. Thereafter various trace gas profiles are retrieved in a successive manner, in which the major species $\mathrm{O}_{3}, \mathrm{H}_{2} \mathrm{O}, \mathrm{CH}_{4}, \mathrm{~N}_{2} \mathrm{O}$, and $\mathrm{HNO}_{3}$ are analyzed first. Beside each target species, microwindow-dependent continuum radiation profiles and microwindow-dependent, but height-independent zero level calibration corrections are jointly fitted. More details on the retrieval strategy are given in, e.g., von Clarmann et al. (2003b), Glatthor et al. (2004), Höpfner et al. (2004), Mengistu Tsidu et al. (2004) and references therein. The retrieval grid used at IMK has an altitude spacing of $1 \mathrm{~km}$ up to $44 \mathrm{~km}$ and of $2 \mathrm{~km}$ between 44 and $70 \mathrm{~m}$, which is considerably finer than the height distance of $\sim 3 \mathrm{~km}$ between the respective tangent altitudes. To avoid consequential instabilities, Tikhonov's first derivative operator is used as smoothing constraint for the retrieval of profiles (Steck, 2002, and references therein).

Instead of analysis of wide spectral bands, generally a set of confined spectral regions, so-called microwindows (MWs), is used for retrieval of the volume mixing ratio (VMR) of ozone or other trace species from midinfrared measurements. The altitude-dependent selection of microwindows is stored in so-called occupation matrices (OMs). In pre-flight studies, microwindow sets were optimized via a quantitative mathematical method by minimizing the estimated retrieval error (von Clarmann and Echle, 1998; Echle et al., 2000). Table 1 shows the microwindow set or occupation matrix, used at IMK for ozone retrieval. It consists of 10 microwindows and, added up over all 17 tangent altitudes, contains 1429 spectral gridpoints. The microwindow width varies between 0.1 and $2.4 \mathrm{~cm}^{-1}$, with an average size of $0.39 \mathrm{~cm}^{-1}$. Six microwindows are situated in MIPAS band A $\left(685-970 \mathrm{~cm}^{-1}\right)$ in the wavenumber region $741-798 \mathrm{~cm}^{-1}$ and 4 microwindows in band $\mathrm{AB}\left(1020-1170 \mathrm{~cm}^{-1}\right)$ in the region $1062-1108 \mathrm{~cm}^{-1}$, each of them used in a specific altitude range. MIPAS band $\mathrm{AB}$ contains the most energetic ozone $v_{1}$ and $v_{3}$ fundamental modes at 1103 and $1042 \mathrm{~cm}^{-1}$, respectively. Lines of these bands are commonly used for ozone retrieval in the middle atmosphere, but often become saturated at lower altitudes. Here the weaker $v_{2}$ fundamental band situated in band A can also be taken into account, but many of these lines are perturbed by the $15 \mu \mathrm{m}$ bands of $\mathrm{CO}_{2}$. Since the ozone retrieval at IMK is performed assuming local thermodynamic equilibrium, the microwindow selection has been optimized such that NLTE emissions are as far as possible excluded. Ozone retrieval of MIPAS scans obtained in "upper atmospheric" mode $(18-100 \mathrm{~km})$ under consideration of NLTE is described by Gil-López et al. (2005).

Figure 1 shows the ozone distribution obtained at IMK (data version V2_O3_2) with the microwindow set shown in Table 1 for MIPAS orbit 8597 of 22 October 2003, which is used as reference (RET_A+AB_MIPAS) in this study. 
Table 1. Microwindow set optimized for a polar atmosphere, used for standard ozone retrieval (RET_A+AB_MIPAS). The left column shows the spectral regions of the different microwindows. The logical matrix in the right column (so-called occupation matrix) defines, at which heights between 6 and $68 \mathrm{~km}$ the respective microwindow is used $(\mathrm{T})$ or not used (=). Heights increase from left to right, and height labels 06 to $68 \mathrm{~km}$ are denoted vertically in the first two rows.

\begin{tabular}{rc}
\hline $\begin{array}{r}\text { Microwindow } \\
\mathrm{cm}^{-1}\end{array}$ & $\begin{array}{c}\text { Altitude coverage } \\
6-68 \mathrm{~km}\end{array}$ \\
& $\begin{array}{c}00111222333344566 \\
69258147036927208\end{array}$ \\
\hline $741.675-741.825$ & $====\mathrm{T}====$ TTTTTTT $=$ \\
$744.950-745.125$ & $=$ TTTTTTTTTTTTTT \\
$757.900-758.000$ & $==$ TTTTTTTTTTT $===\mathrm{T}$ \\
$759.225-761.650$ & TTTT $==$ TTTTTTTTTTT \\
$764.800-764.950$ & T==TTTTTT $==$ TT $=$ TTT \\
$798.450-798.650$ & $===$ TTTTTTTTTTTT \\
$1062.325-1062.475$ & $====\mathrm{T}========$ TTT \\
$1081.500-1081.600$ & TTTTT=TTTTTTTTTT \\
$1090.350-1090.475$ & TTTTT $=$ TTTTTTTTTTT \\
$1108.000-1108.350$ & TTT=T $===$ TT $=$ T $=====$ \\
\hline
\end{tabular}
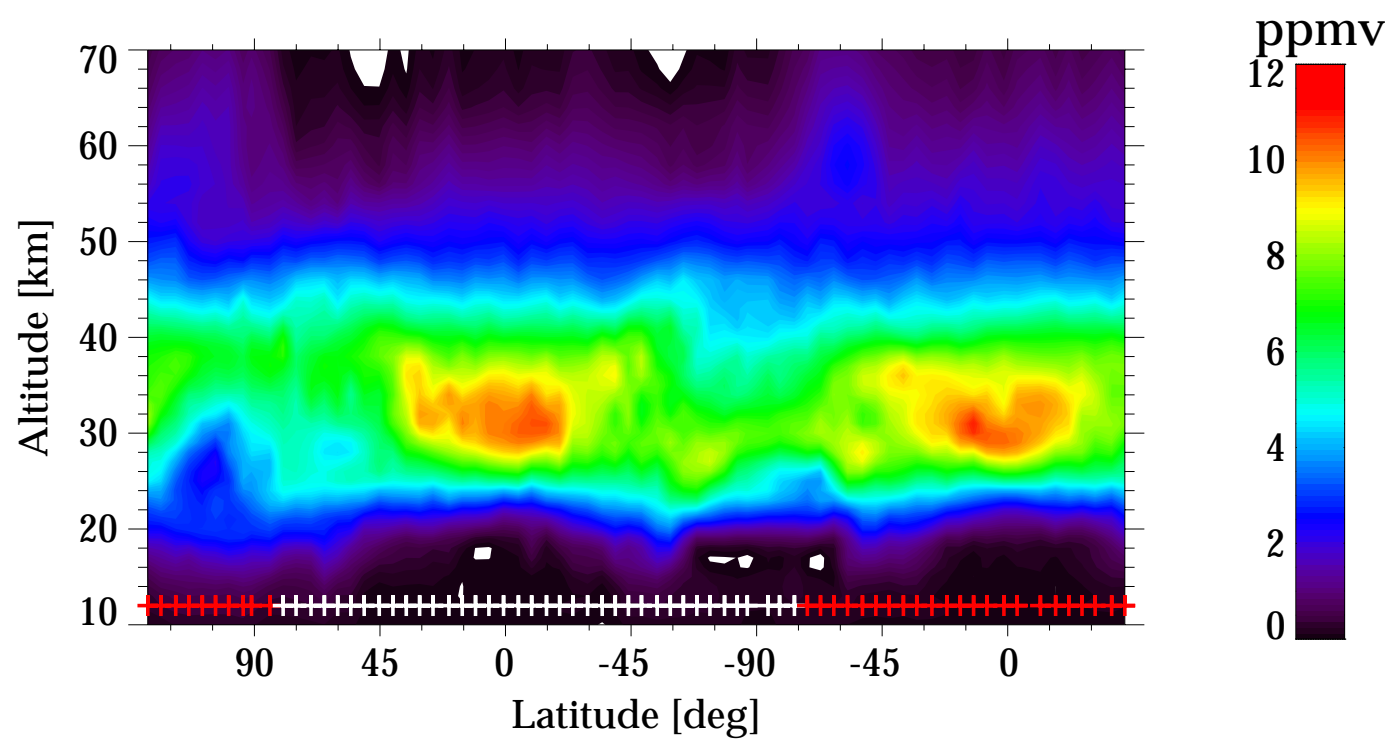

Fig. 1. Reference ozone distribution (RET_A+AB_MIPAS, data version V2_O3_2), derived from MIPAS limb-scans along orbit 8597 of 22 October 2003, 16:15-17:53 UT, plotted versus geographic latitude and altitude. Plus signs indicate the latitudinal locations of the limb-scans on the daytime (white signs) and nighttime part (red signs) of the orbit; the small white areas indicate retrieved volume mixing ratios below 0 ppmv (due to profile oscillations).

Daytime measurements, indicated by white plus signs, were generally performed on the southward leg of the orbit and nighttime measurements (red plus signs) on the northward leg. Because of the season the day/night terminators are shifted towards $80^{\circ}$ and $-80^{\circ}$. The tropical and subtropical $\mathrm{O}_{3}$ VMR maximum of $12 \mathrm{ppmv}$ is in the altitude region $30-35 \mathrm{~km}$, exhibiting no distinct variation between day and night. The Arctic maximum of about 7 ppmv is situated around $38 \mathrm{~km}$, whereas the Antarctic maximum of about 8 ppmv is just below $30 \mathrm{~km}$. The low Arctic ozone amounts in the altitude region $24-32 \mathrm{~km}$ reflect the climatological minimum of total ozone in autumn. Different from the stratosphere there is a clear variation in the mesosphere, with nearly disappearing daytime ozone and nighttime mixing ratios of up to $2 \mathrm{ppmv}$ around $60^{\circ}$ and $-60^{\circ}$. This is the tertiary ozone maximum just equatorward of the polar night terminator as described by Marsh et al. (2001). 

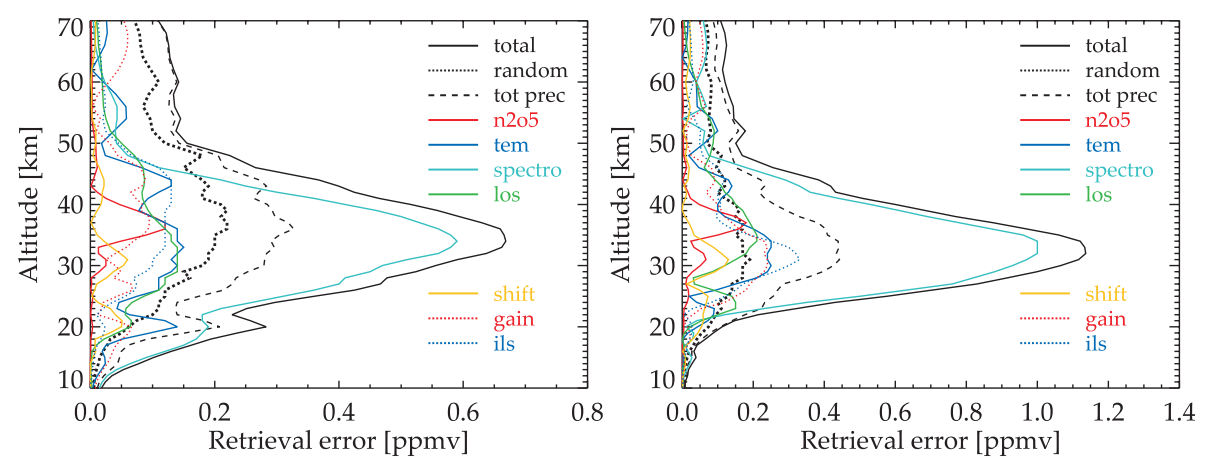

Fig. 2. $\mathrm{O}_{3}$ retrieval error of standard retrieval for a polar (left) and a tropical (right) geolocation of the dayside part of orbit 8597 . Solid black: total error, dotted black: noise error, dashed black: total precision; the error components shown (cf. legend) are the error caused by uncertainty in the $\mathrm{N}_{2} \mathrm{O}_{5}$ amount, in temperature, in spectroscopic data, in the instrumental line-of-sight (los), in spectral shift, in gain calibration, and in the instrumental line shape (ils).

71 individual ozone profiles, which cover a range of atmospheric conditions, namely the Arctic pre-vortex, northern fall and southern spring mid-latitudes, the tropics and the final stage of the Antarctic vortex, were derived from orbit 8597 . Nevertheless, to obtain a more representative picture, orbits 5852 from 13 April and 7274 from 22 July 2003, i.e. from two different seasons, were also included in the sensitivity study.

Figure 2 shows the total estimated ozone retrieval error, measurement noise, the total precision and the major error components for a polar (left) and a tropical geolocation (right). The total precision contains all error components, which interact as random error sources, i.e. all error contributions except uncertainties in spectroscopic data, in the instrumental line shape (ILS) and uncertainties resulting from phenomena not included in the forward calculation like NLTE effects. This error estimation is based on the actual retrieved temperatures, tangent heights, ozone mixing ratios, simulated spectra and Jacobians of the final iteration (cf. Glatthor et al., 2004). The maximum total error is $0.65 \mathrm{ppmv}$ at the polar and $1.2 \mathrm{ppmv}$ at the tropical geolocation and exceeds $0.2 \mathrm{ppmv}$ in the altitude region 20 to $50 \mathrm{~km}$. In both cases the measurement noise is mostly between 0.1 and $0.2 \mathrm{ppmv}$, whereas the total precision at the altitude of the ozone maximum is $0.3 \mathrm{ppmv}$ at the polar and $0.45 \mathrm{ppmv}$ at the tropical geolocation. The maximum uncertainty at mid-latitudes (not shown) is typically $0.8 \mathrm{ppmv}$. In relative units, the total error is around $10 \%$ and the noise error is below $4 \%$ in the altitude region from 10 to $45 \mathrm{~km}$ at the polar geolocation. At the tropical geolocation, the relative total error is between $5 \%$ and $10 \%$ in the height region $25-50 \mathrm{~km}$, whereas the relative noise error is below 3\%. In both cases, the estimated uncertainty in spectroscopic data is the dominant error source. This error contribution was calculated from the uncertainties in line intensity given by Flaud et al. (2003) and from the error in half-width listed in the HIgh-resolution TRANs- mission (HITRAN) database (Rothman et al., 1998). More details on spectroscopic errors are given in Sect. 3.3.3. Further important error sources are uncertainties in the retrieved temperature and tangent altitudes, in spectral gain calibration and in the assumed instrumental line shape.

The rms deviation between ozone measured by MIPAS and the HALogen Occultation Experiment (HALOE) on the Upper Atmospheric Research Satellite (UARS), as calculated in a validation study for the period 30 October to 7 November 2003 , is $0.7 \mathrm{ppmv}$ at $30 \mathrm{~km}$ and decreases to $0.2 \mathrm{ppmv}$ at $50 \mathrm{~km}$ and to $0.5 \mathrm{ppmv}$ at $20 \mathrm{~km}$ altitude. These values are of the order of the total estimated retrieval error and thus show satisfactorily agreement between both instruments. The methodology of this validation study is described more in detail by Wang et al. (2005).

\section{Sensitivity studies}

In order to optimize the retrieval setup, the following issues have been investigated: The dependence of the ozone retrieval on the cloud detection scheme, on the treatment of the background continuum, on the MIPAS band used for retrieval, and on the regularization chosen.

\subsection{Influence of the cloud-index}

The signal obtained by MIPAS from the lower atmosphere is often contaminated by tropospheric or polar stratospheric clouds, which trigger errors in the retrieval of trace gas amounts at these altitudes. Therefore spectra from tangent altitudes below $30 \mathrm{~km}$ are checked by a cloud-detection algorithm, which calculates the ratio between the measured radiances in the wavenumber ranges 788.2-796.25 and 832.3$834.4 \mathrm{~cm}^{-1}$. This ratio, the so-called cloud-index, decreases with increasing cloud-contamination (Spang et al., 2004). For ozone data versions V2_O3_2 and lower, spectra with 

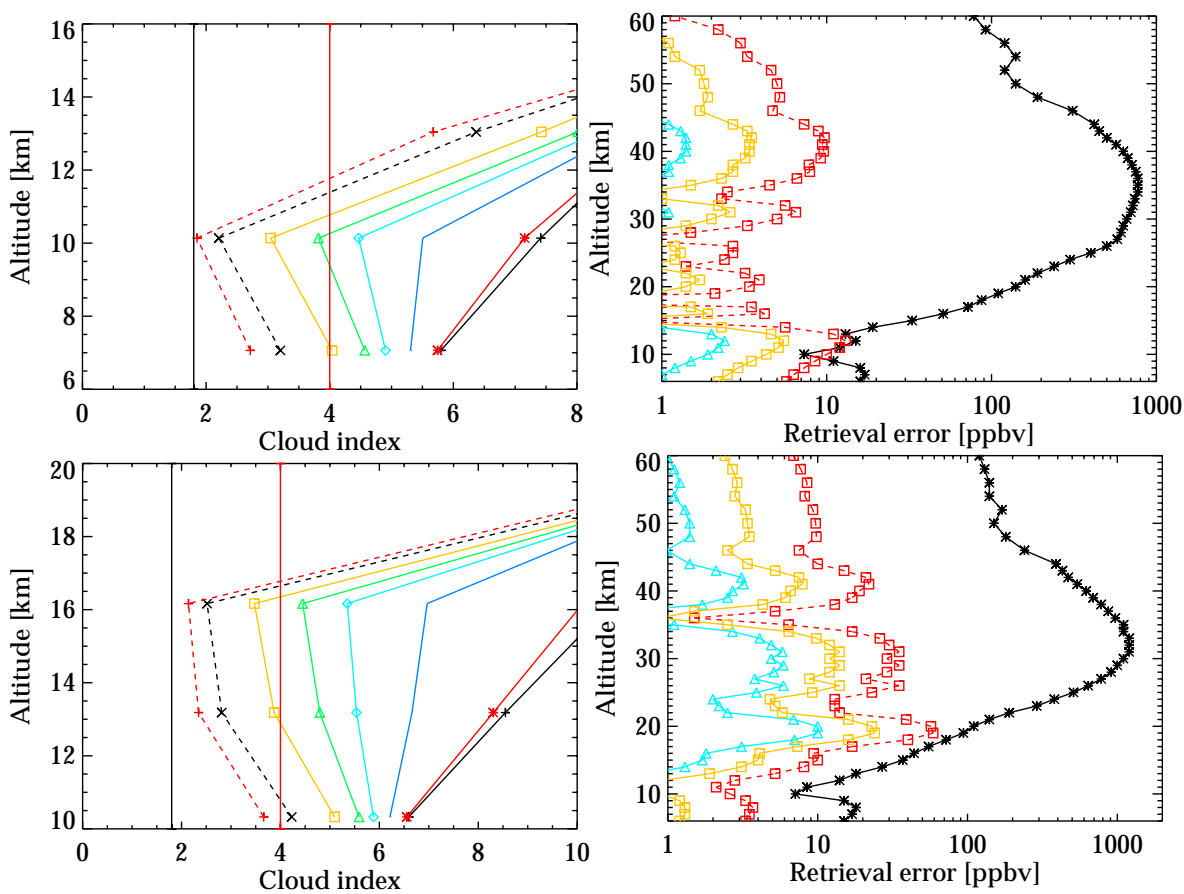

Fig. 3. Top left: Cloud-indices, calculated from synthetic spectra containing a cirrus cloud between 10 and $11 \mathrm{~km}$ altitude, for a midlatitude geolocation $\left(46.1^{\circ} \mathrm{N}\right)$ of orbit 8597. The rightmost curve (solid black) is the reference for a cloud-free atmosphere. From right to left, the other curves were calculated for increasing particle densities of $1 \times 10^{-4}, 1 \times 10^{-3}, 2 \times 10^{-3}, 3 \times 10^{-3}, 5 \times 10^{-3}, 1 \times 10^{-2}$ and $1.5 \times 10^{-2} \mathrm{~cm}^{-3}$. The vertical lines indicate cloud thresholds of 1.8 and 4.0. Top right: Corresponding ozone retrieval error. Black curve: total retrieval error of reference calculation; light blue, yellow and red curves: additional retrieval error caused by cloud layers between 10 and $11 \mathrm{~km}$ with particle densities of $2 \times 10^{-3}, 5 \times 10^{-3}$ and $1.5 \times 10^{-2} \mathrm{~cm}^{-3}$, respectively. Bottom: same as upper panel, but for a cirrus cloud between 15.5 and $16.5 \mathrm{~km}$ at a tropical geolocation $\left(8.6^{\circ} \mathrm{S}\right)$.

cloud-indices below 1.8 were rejected from analysis. The same value is used in the operational data analysis under ESA responsibility. This threshold was suggested by Spang et al. (2004) for the altitude region $10-45 \mathrm{~km}$. In choosing this value, these authors in tendency minimized the risk to exclude a cloud-free spectrum due to an over-sensitive cloudindex. However, they were aware that only an index of 4 or higher guarantees exclusion of optically thin clouds like PSCs or high cirrus clouds.

In IMK retrievals, inclusion of spectra containing thin upper tropospheric clouds often turned out as unfavourable. Therefore we choose the opposite approach and assess the risk that a cloud-contaminated spectrum is regarded as cloudfree. This approach, however, requires cloud radiative transfer modelling (Höpfner et al., 2005). As a first step, we simulated limb emission spectra by radiative transfer calculations for an atmosphere with different cirrus cloud layers between 10 and $11 \mathrm{~km}$ altitude consisting of $5 \mu \mathrm{m}$ particles with varying particle densities (particle densities falling to zero towards 9 and $12 \mathrm{~km})$ at a northern mid-latitude $\left(46.1^{\circ} \mathrm{N}\right)$ geolocation, as well as for different cirrus cloud layers between 15.5 and $16.5 \mathrm{~km}$ altitude at a tropical geolocation $\left(8.6^{\circ} \mathrm{S}\right)$. The resulting cloud indices are presented in Fig. 3 (left panel). The rightmost curve is the reference for a cloud- free atmosphere and shows that a cloud-index of 5.5 or higher would even reject cloud-free spectra at the lowermost tangent altitude. From right to left, the other curves represent cloud indices resulting from clouds with particle densities increasing from $1 \times 10^{-4}$ (cloud 1) to $1.5 \times 10^{-2} \mathrm{~cm}^{-3}$ (cloud 7). Beginning with cloud 3 (light blue curve) they exhibit local minima between 4.6 and 1.8 at the altitude of the mid-latitude cloud layer and between 5.4 and 2.1 at the height of the tropical cloud layer. Similar cloud indices were also obtained for an antarctic PSC layer of alpha-NAT particles between 20 and $21 \mathrm{~km}$ (not shown) with comparable particle densities as in the midlatitude and tropical case.

In order to investigate the impact on the retrieval, the error triggered by the cloud signal was estimated by multiplication of the retrieval gain function of this geolocation with the difference of the cloud-contaminated and cloud-free spectral signal:

$$
\left(\mathbf{K}^{T} \mathbf{S}_{y}^{-1} \mathbf{K}+\mathbf{R}\right)^{-1} \mathbf{K}^{T} \mathbf{S}_{y}^{-1}(\mathrm{~F}(\boldsymbol{x}, \mathrm{cl})-\mathrm{F}(\boldsymbol{x}, \mathrm{clfr})),
$$

where $\mathrm{F}(\boldsymbol{x}, \mathrm{cl})$ and $\mathrm{F}(\boldsymbol{x}, \mathrm{clfr})$ are spectra simulated for a cloudy and cloud-free atmosphere, respectively. Figure 3 (top right) shows the total ozone retrieval error of the reference calculation and the additional error components 
Table 2. Orbit-averaged heights of the lowest tangent altitude (ltgh) of MIPAS scans remaining after application of cloud-threshold 1.8 and 4.0, respectively, and height difference between both applications. Height averages were calculated for three different orbits, for polar (ltgh pol), mid-latitude (ltgh midl) and tropical (ltgh trop) geolocations, respectively.

\begin{tabular}{llllll}
\hline Orbit & Date & $\begin{array}{l}\text { Cloud } \\
\text { index }\end{array}$ & $\begin{array}{l}\text { ltgh pol } \\
{[\mathrm{km}]}\end{array}$ & $\begin{array}{l}\text { ltgh midl } \\
{[\mathrm{km}]}\end{array}$ & $\begin{array}{l}\text { ltgh trop } \\
{[\mathrm{km}]}\end{array}$ \\
\hline 5852 & \multirow{2}{*}{ 13 April 2003 } & 1.8 & 7.77 & 10.96 & 15.95 \\
& & 4.0 & 9.71 & 12.05 & 17.12 \\
& & & 1.94 & 1.09 & 1.17 \\
7274 & \multirow{2}{*}{ 22 July 2003 } & 1.8 & 13.94 & 10.53 & 12.40 \\
& & 4.0 & 15.54 & 12.34 & 14.92 \\
& & & 1.60 & 1.81 & 2.52 \\
8597 & \multirow{2}{*}{ 22 October 2003 } & 1.8 & 8.88 & 9.01 & 11.19 \\
& & 4.0 & 10.60 & 11.07 & 14.20 \\
& & & 1.72 & 2.06 & 3.01 \\
\hline
\end{tabular}
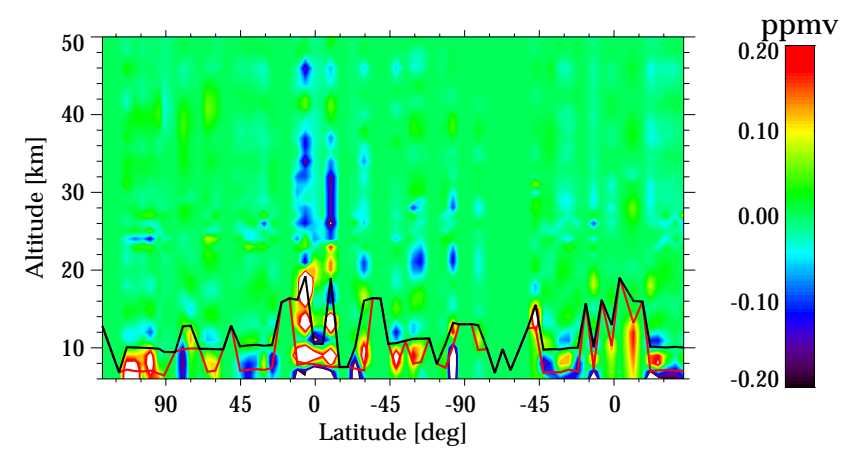

Fig. 4. Difference between retrieval with cloud-threshold 4.0 and 1.8 (RET_A+AB_MIPAS). The red and black curves show the lowermost tangent heights taken into account for retrieval after application of cloud-threshold 1.8 and 4.0, respectively.

resulting from the mid-latitude cloud layers with particle densities of $2 \times 10^{-3}, 5 \times 10^{-3}$ and $1.5 \times 10^{-2} \mathrm{~cm}^{-3}$, which in our model calculation are related to cloud-indices of 4.5 , 3.1 and a value of just above 1.8, respectively (Fig. 3, left). The additional uncertainty caused by the cloud of lowest particle density is small in comparison to the total retrieval error, whereas in the other two cases it is between 30 and $140 \%$ of the total error in the altitude region 9 to $13 \mathrm{~km}$ and propagates upward throughout the whole stratosphere. The maximum additional error caused by the tropical cirrus clouds of the same particle densities is 10, 25 and $60 \%$ of the total error at $20 \mathrm{~km}$ altitude (Fig. 3, bottom right). However, due to the higher altitude of the tropical cloud the error propagated upward into the mid-stratosphere is larger. Moreover, these values are lower estimates of the uncertainties due to the clouds, because cloud-induced temperature or pointing errors and scattering of lower atmosperic radiation into the line-of-sight are not taken into account. Although for re- trieval of ozone, a cloud threshold of 3 may be considered sufficient, we have decided to increase the cloud threshold from 1.8 to 4 . The more conservative value of 4 for IMK retrievals was chosen mainly with regard to retrieval of other species, which is even more sensitive to clouds.

Figure 4 shows the difference in retrieved ozone between application of the high (4.0) and low (1.8) cloud-index along with the lowermost tangent altitudes taken into account in both cases. Differences below the lowest tangent height considered after application of cloud index 4.0 (black curve) are not relevant. The influence of the increased cloud-index on the retrieved stratospheric ozone amounts is of the order of the estimated error caused by clouds (cf. Fig. 3, right) in those regions, where the effect of the two cloud-filters is not much different. Between $10^{\circ}$ and $-20^{\circ}$ in the dayside tropics, where, due to high optically thin clouds, the number of tangent altitudes additionally excluded by the increased cloud threshold is largest, there are mainly negative differences of up to $-0.15 \mathrm{ppmv}$ in the altitude region $20-40 \mathrm{~km}$. These deviations are somewhat larger than the estimated tropical cloud-induced error, because the relative weight of the regularization increases by rejection of a large number of spectra from the retrieval. Table 2 shows the heights of the lowest tangents of the MIPAS scans remaining after application of cloud-index 1.8 and 4.0 and the resulting differences for the three investigated orbits. The values given are averages for polar, midlatitude and tropical geolocations, respectively. The differences vary between $1.1 \mathrm{~km}$ for mid-latitude geolocations of orbit 5852 and $3.0 \mathrm{~km}$ for tropical geolocations of orbit 8597. That means that even in the last case on average only one additional tangent altitude is rejected by the more stringent cloud-threshold. 

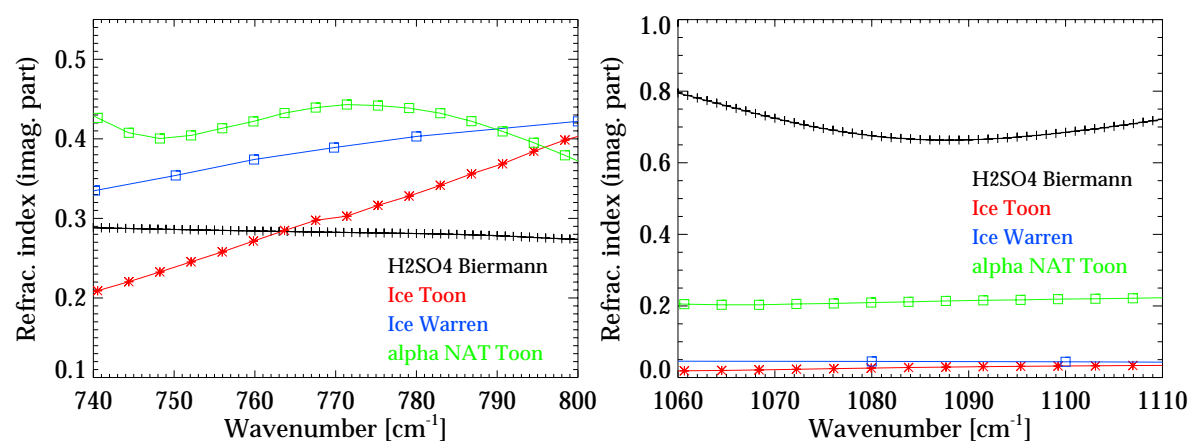

Fig. 5. Imaginary parts of refractive indices of a 75 weight-percent solution of $\mathrm{H}_{2} \mathrm{SO}_{4}$ in $\mathrm{H}_{2} \mathrm{O}$ at $190 \mathrm{~K}$ provided by Biermann et al. (2000) (black curve), of ice particles provided by Toon et al. (1994) (red curve) and Warren (1984) (blue curve), and of alpha-NAT of Toon et al. (1994) (green curve) for the ozone microwindow regions in MIPAS band A (left) and AB (right).

3.2 Influence of the treatment of background continuum emission

The basic retrieval strategy, applied at IMK as well as by most other research groups for MIPAS data processing, is to retrieve the background continuum emission per altitude and per microwindow simultaneously to the target species abundance (von Clarmann et al., 2003b). The rationale of this approach is, first, not to rely on aerosol, cloud and gas climatologies but to use the actual values in the radiative transfer forward modelling, and second to compensate for spectral residuals caused by any other weakly wavenumberdependent signal not properly accounted for by the radiative transfer calculation, such as far wings of remote spectral lines.

In the MIPAS-IMK-IAA data processor the continuum is constrained to zero (hard constraint) above $32 \mathrm{~km}$, because these altitudes are assumed to be free of aerosols. Below this altitude a Tikhonov smoothing constraint is applied both in the altitude and the wavenumber domain. Additionally, an altitude-constant additive radiance calibration correction is retrieved per microwindow.

Here we assess, if a $5 \mathrm{~cm}^{-1}$ representation of the empirical background continuum, i.e. assignment of a common continuum profile to spectrally adjacent microwindows, is sufficient to serve the purpose outlined above. Such a representation comprises a reduction in retrieval variables, which can reduce the computational burden considerably. For this purpose, we investigate the wavenumber dependence of aerosol and cloud spectra as well as of gas continua found in the literature, and discuss the wavenumber dependence of continua retrieved with MIPAS. Further we show the difference in retrieved ozone resulting from assuming one background continuum profile per microwindow and a locally flat continuum over $5 \mathrm{~cm}^{-1}$.

To approximate the aerosol particle distribution we used measurements of Deshler et al. (2003) from 20 April 1999, which fall into the same period of continuously low stratospheric aerosol loading prevailing since the late 1990s as the MIPAS campaign, and from 19 March 1993, which were performed in volcanic aerosol. For both measurements we assumed bimodal aerosol distributions between 10 and $30 \mathrm{~km}$ altitude with size distributions as given in Deshler et al. (2003), i.e. particle densities of 7.67 and $0.006 \mathrm{~cm}^{-3}$ and mode radii of 0.069 and $0.42 \mu \mathrm{m}$ for the background aerosol and particle densities of 3.99 and $1.63 \mathrm{~cm}^{-3}$ and mode radii of 0.13 and $0.41 \mu \mathrm{m}$ for the volcanic aerosol. The wavenumber dependence of the aerosol absorption was modelled using the refractive indices (imaginary parts) of a 75 weightpercent solution of $\mathrm{H}_{2} \mathrm{SO}_{4}$ in $\mathrm{H}_{2} \mathrm{O}$ at $190 \mathrm{~K}$ by Biermann et al. (2000) (Fig. 5). Clouds are assumed not to be represented by the fitted continuum, because cloud-contaminated spectra are generally rejected from the retrieval by the algorithm described in Sect. 3.1. As we had shown this is not the case for rather thin clouds. Therefore we also analysed the effect of upper tropospheric cirrus clouds and polar stratospheric clouds (PSCs) not rejected by the cloud filter using the wavenumber-dependent refractive indices (imaginary parts) of ice and nitric acid trihydrate (NAT) by Toon et al. (1994) (Fig. 5). For comparison the coarser resolved refractive indices of ice by Warren (1984) are also shown, but not further utilized. The wavenumber dependence of all these refractive indices of aerosols, ice and NAT is rather smooth in the microwindow regions in MIPAS band A $\left(740-800 \mathrm{~cm}^{-1}\right)$ as well as in band AB $\left(1060-1110 \mathrm{~cm}^{-1}\right)$, but some of them show a distinct slope.

To quantify the effect of applying a spectrally locally flat continuum in evaluation of MIPAS data, synthetic spectra containing aerosols, ice clouds or NAT-PSCs were calculated for mid-latitude, tropical and polar geolocations of orbit 8597 in two different ways. First, the refractive indices given in original spectral resolution were used, and then similar calculations were performed with refractive indices represented by staircase functions sampled at $5 \mathrm{~cm}^{-1}$ for the aerosol and at about $8 \mathrm{~cm}^{-1}$ for the ice clouds and NATPSCs. The larger stepwidth for the ice clouds and the PSCs was chosen, because the original data have a spectral resolution of $4 \mathrm{~cm}^{-1}$ only (cf. Fig. 5). At the northern mid-latitude 

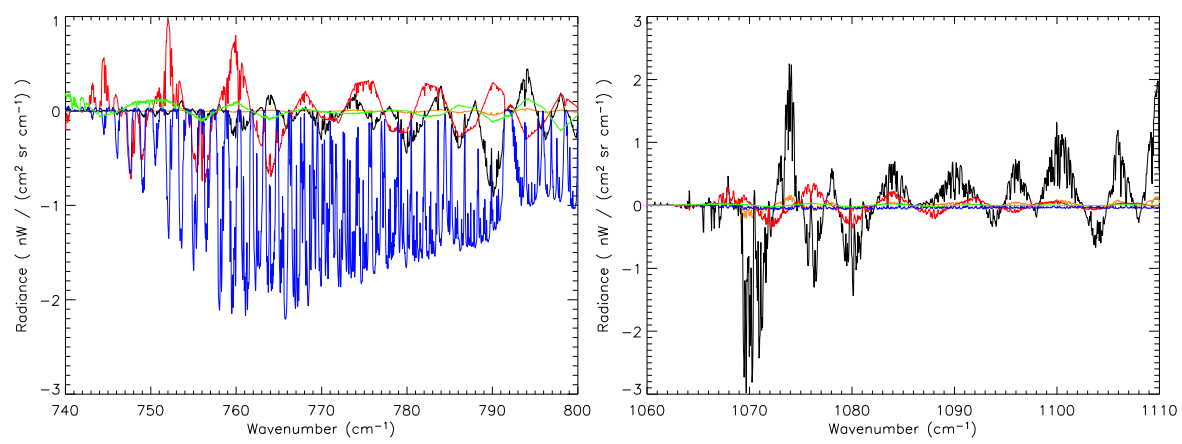

Fig. 6. Left: Differences between synthetic spectra calculated for the ozone microwindow region in MIPAS band A with original refractive indices of aerosol (Biermann), ice and alpha-NAT (Toon) and representation by $5 \mathrm{~cm}^{-1}$ (aerosol) and $8 \mathrm{~cm}^{-1}$ (ice, alpha-NAT) staircase functions, respectively; brown and black curves: differences for background and volcanic aerosol (tangent altitude 10.1 km); red curve: difference for ice (tangent altitude $10.1 \mathrm{~km}$ ); green curve: difference for alpha-NAT (tangent altitude 19.3 km); blue curve: difference between the $\mathrm{H}_{2} \mathrm{O}$ and $\mathrm{CO}_{2}$ continua calculated for the reference atmosphere and for $\mathrm{H}_{2} \mathrm{O}$ and $\mathrm{CO}_{2}$ amounts scaled by factors 0.9 and 0.99 (tangent altitude $10.1 \mathrm{~km}$ ). Right: same as left, but for the ozone microwindow region in MIPAS band AB.
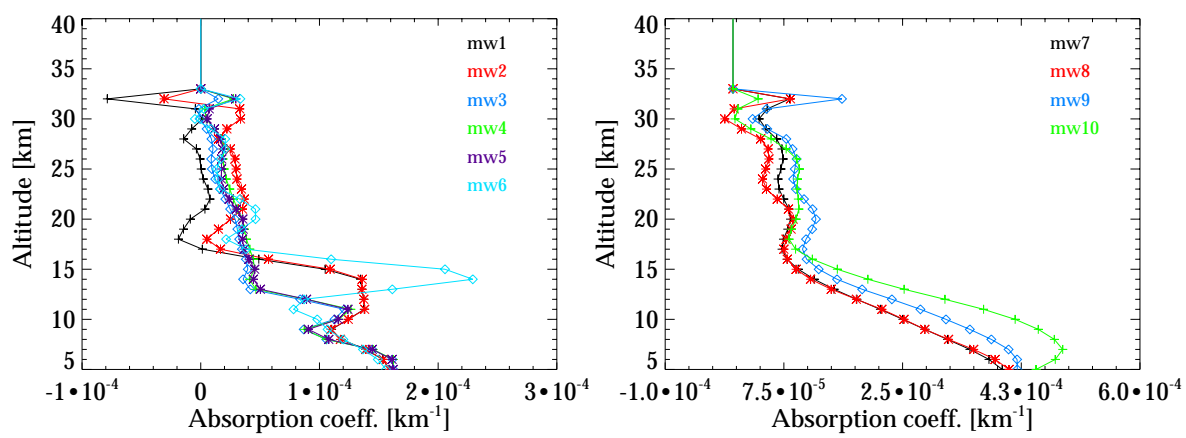

Fig. 7. Orbit-averaged continuum profiles of orbit 8597 retrieved in ozone microwindows 1-6 (left) and 7-10 (right) (cf. Table 1). Assignment to microwindows is colour-coded in the legend.

geolocation $\left(46.1^{\circ} \mathrm{N}\right)$, the maximum differences at the tangent altitude of $10.1 \mathrm{~km}$ between original and degraded representation were $\pm 0.2 \mathrm{nW} /\left(\mathrm{cm}^{2} \mathrm{srcm}^{-1}\right)$ for the background aerosol, $\pm 3.0 \mathrm{nW} /\left(\mathrm{cm}^{2} \mathrm{sr} \mathrm{cm}^{-1}\right)$ for the volcanic aerosol and $\pm 1.0 \mathrm{nW} /\left(\mathrm{cm}^{2} \mathrm{srcm}^{-1}\right)$ for ice cloud 3 with a particle density of $2 \times 10^{-3} \mathrm{~cm}^{-3}$ (Fig. 6), which still had passed the increased cloud threshold of 4.0 (cf. Sect. 3.1). The maximum difference for the antarctic PSC $\left(86.2^{\circ} \mathrm{S}\right)$ between 20 and 21 $\mathrm{km}$ with a particle density of $4 \times 10^{-3} \mathrm{~cm}^{-3}$, which also is still accepted as cloud-free by the increased cloud threshold of 4.0 , was below $\pm 0.35 \mathrm{nW} /\left(\mathrm{cm}^{2} \mathrm{srcm}^{-1}\right)$ at the tangent altitude of $19.3 \mathrm{~km}$. These deviations are very small in comparison to the noise equivalent spectral radiance (NESR), which decreases from 25 to $18 \mathrm{nW} /\left(\mathrm{cm}^{2} \mathrm{srcm}^{-1}\right)$ and from 16.5 to $12 \mathrm{nW} /\left(\mathrm{cm}^{2} \mathrm{srcm}^{-1}\right)$ in the microwindow regions in MIPAS band $\mathrm{A}$ and $\mathrm{AB}$, respectively. The retrieval error caused by this simplified representation of the refractive indices was additionally estimated by multiplication of these difference spectra with the retrieval gain function

$$
\left(\mathbf{K}^{T} \mathbf{S}_{y}^{-1} \mathbf{K}+\mathbf{R}\right)^{-1} \mathbf{K}^{T} \mathbf{S}_{y}^{-1} \times(\mathrm{F}(\boldsymbol{x}, \text { fine })-\mathrm{F}(\boldsymbol{x}, \text { coarse })),
$$

where $\mathbf{K}$ is the Jacobian of the retrieval, and $\mathrm{F}(\boldsymbol{x}$, fine $)$ and $\mathrm{F}(\boldsymbol{x}$, coarse $)$ are the spectra with full resolved and 5 or $8 \mathrm{~cm}^{-1}$ continuum representation. The resulting uncertainty was less than $0.1 \%$ for aerosol and even for the strongest ice cloud with a particle density of $1.5 \times 10^{-2} \mathrm{~cm}^{-3}$ (cf. Sect. 3.1).

In the mid-infrared, the contribution of far wings of the large amount of lines of strong absorbers like $\mathrm{H}_{2} \mathrm{O}$ and $\mathrm{CO}_{2}$ also causes a continuum-like absorption. The forward model KOPRA (Karlsruhe Optimised and Precise Radiation Algorithm, Stiller, (Ed.), 2000) used at IMK enables modelling of these continua. The $\mathrm{H}_{2} \mathrm{O}$ continuum is calculated using the CKDv2.2 model of Clough (1995) and the $\mathrm{CO}_{2}$ continuum using the models for far wing line shapes of Menoux et al. $(1987,1991)$ and Cousin et al. (1985). Since these continua are explicitely modeled, only the deviation of the actual continuum from the modeled one, driven by deviations between assumed and actual abundances of related gases, has to be compensated by the empirically fitted continuum.

To estimate the effect of not completely compensated gas continua, $\mathrm{H}_{2} \mathrm{O}$ and $\mathrm{CO}_{2}$ continua were calculated for $\mathrm{H}_{2} \mathrm{O}$ and $\mathrm{CO}_{2}$ amounts scaled down by 10 and $1 \%$, 
respectively, and subtracted from spectra containing the reference gas continua (Fig. 6, blue curves). The maximum differences are $-2 \mathrm{nW} /\left(\mathrm{cm}^{2} \mathrm{srcm}^{-1}\right)$ in band $\mathrm{A}$ and $-0.07 \mathrm{nW} /\left(\mathrm{cm}^{2} \mathrm{srcm}^{-1}\right)$ in band $\mathrm{AB}$, which is also small compared to the NESR. In summary, the investigated aerosol, cloud and gas continua give no evidence that a continuum representation degraded to $5 \mathrm{~cm}^{-1}$ in wavenumber space has a significant impact on the ozone retrievals.

Figure 7 shows the orbit-averaged continuum profiles retrieved in microwindows 1-6 in MIPAS band A (left) and in MWs 7-10 in MIPAS band AB (right). Application of the $5 \mathrm{~cm}^{-1}$ criterion to the ozone occupation matrix would lead to a common background continuum for microwindows 1 and 2 as well as 3 and 4 (cf. Table 1). The individual continua retrieved in these spectrally adjacent MWs (black and red as well as dark blue and green curves in the left graph) show only a rather small difference, and thus also justify the intended approach. The negative and positive spikes appearing in all microwindows at $32 \mathrm{~km}$ are not caused by insufficient spectral sampling, but rather by setting the continum zero above $32 \mathrm{~km}$.

Finally the sensitivity of the retrieved ozone profiles to the different treatment of the background continuum (one continuum profile for each microwindow or common continuum profiles for MWs 1 and 2 as well as 3 and 4) was tested. Differences mainly occur in the altitude region $15-40 \mathrm{~km}$ and are less than \pm 0.2 ppmv at most latitudes (Fig. 8). Unexpectedly, the sensitivity to this change of continuum treatment is largest (up to $-0.3 \mathrm{ppmv}$ ) at altitudes around $32 \mathrm{~km}$, where the contribution of the atmospheric continuum is close to zero. However, at this height the spikes in the continuum profiles occur, and, different from all altitudes below, MWs 1 and 2 as well as 3 and 4 are all included in the microwindow set (cf. Table 1). Nevertheless, the differences are generally smaller than the total estimated retrieval error, (cf. Fig. 2). Similar deviations were obtained for orbits 5852 and 7274 (not shown here). The altitude of the major deviations (around $30 \mathrm{~km}$ ) indicates that the continuum here compensates for a spectral residual caused by any other variable of the forward model, because the smoothness constraint of the ozone retrieval prohibits an exact spectral fit. As a result of all investigations presented in this section, assignment of a common continuum to microwindows less than $5 \mathrm{~cm}^{-1}$ apart, is justified.

\subsection{Band dependence of retrieved ozone profiles}

During our investigations of different microwindow selections it turned out that occupation matrices containing ozone lines from different spectral regions produced systematically different results. Figure 9 (top) shows the deviations between retrieval with an occupation matrix restricted to MIPAS band AB (MWs between 1040 and $1164 \mathrm{~cm}^{-1}$, RET_AB_MIPAS) and retrieval with an occupation matrix confined to band $\mathrm{A}$ (MWs from 730 to $798 \mathrm{~cm}^{-1}$, RET_A_MIPAS), respectively.

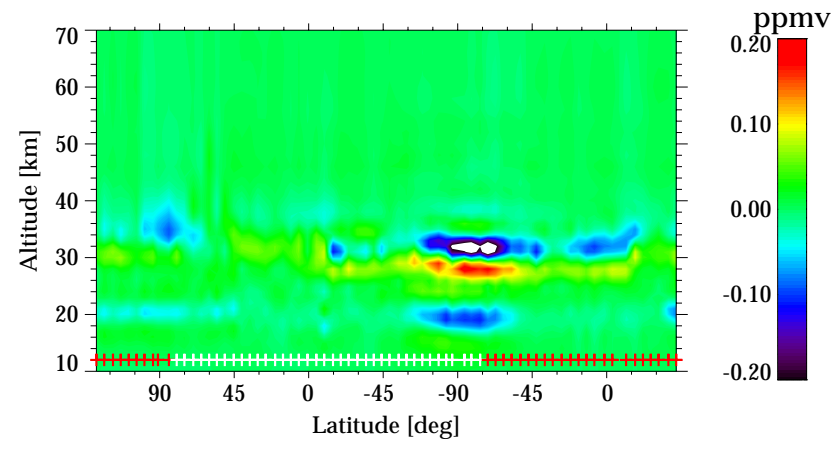

Fig. 8. Difference between retrieval with assignment of a common continuum background emission profile to adjacent microwindows within a $5 \mathrm{~cm}^{-1}$ spectral range and retrieval with individual continuum profiles for every microwindow (RET_A+AB_MIPAS). Same meaning of plus signs as in Fig. 1.

Especially at mid-latitudes and in the tropics there are wide areas with positive differences of about $1 \mathrm{ppmv}$ in the altitude region 28 to $42 \mathrm{~km}$, somewhat more distinct during daytime than at night. The orbit-averaged difference in the altitude band $25-43 \mathrm{~km}$ is $0.40 \mathrm{ppmv}$ (Table 3). Rather similar patterns were also found for the two other orbits from 13 April and 22 July, 2003, with orbit-averaged differences of 0.28 and 0.37 ppmv, respectively (Table 3 ). The following possible explanations for this bias were assessed: (a) nonlocal thermodynamic equilibrium emissions which are not accounted for in the retrieval, (b) gain calibration inconsistencies, and (c) inconsistencies of spectroscopic data in different ozone bands, because the most prominent ozone transitions in the microwindow region from band $\mathrm{A}$ are from the $v_{2}$ fundamental band, while the strongest transitions in the microwindow region from band $\mathrm{AB}$ are from the $v_{1}$ and $v_{3}$ fundamental bands.

\subsubsection{Non-local thermodynamic equilibrium effects}

A possible reason for the discrepancy of ozone retrievals in the two MIPAS bands could be different strengths of nonlocal thermodynamic equilibrium (non-LTE) effects. In the routine IMK ozone retrievals time consuming NLTE calculations are not taken into account in the radiative transfer calculations, because NLTE effects are generally small in the stratosphere, and IMK microwindows are selected such that spectral regions, where these effects are important, are avoided. Nevertheless, as a check, non-LTEretrievals were performed at IAA using the same microwindows in MIPAS bands A (RET_A_MIPAS_NLTE) and AB (RET_AB_MIPAS_NLTE). The result was that consideration of NLTE reduces the bias between band A and AB retrievals by about $30 \%$ (Fig. 9, middle; Table 3). Neglection of nonLTE thus explains a fraction of the bias, but is not the dominant cause. 
Table 3. Orbit-averaged ozone volume mixing ratios(VMRs) [ppmv] in the altitude band $25-43 \mathrm{~km}$ for different microwindow selections and retrieval setups $\mathrm{RET}_{\ldots} . .$. . RET_A+AB_MIPAS: reference retrieval (V2_O3_2) with standard OM containing microwindows in MIPAS bands A and AB (cf. Table 1) and using the MIPAS spectroscopy. Meaning of substrings in the other retrieval setups: A: microwindows in MIPAS band A in wavenumber region $730-800 \mathrm{~cm}^{-1}$ only; A_ $\nu_{3}$ : microwindows in MIPAS band A in wavenumber region $960-970 \mathrm{~cm}^{-1}$ ( $v_{3}$ ozone band) only; AB: microwindows in MIPAS band AB only; NLTE: retrieval including modelling of non-LTE effects; MIPAS: ozone lines from MIPAS datbase; HIT96: ozone lines from HITRAN96 database.

\begin{tabular}{llll}
\hline Orbit & 5852 & 7274 & 8597 \\
Date & 13 April 2003 & 22 July 2003 & 22 Oct 2003 \\
\hline RET_A+AB_MIPAS & 6.784 & 6.373 & 6.840 \\
RET_A_v3_MIPAS & 7.125 & 6.761 & 7.136 \\
RET_AB_MIPAS & 6.855 & 6.587 & 7.060 \\
RET_A_MIPAS & 6.608 & 6.222 & 6.659 \\
Difference AB-A & 0.277 & 0.365 & 0.401 \\
RET_AB_MIPAS_NLTE & - & - & 6.916 \\
RET_A_MIPAS_NLTE & - & - & 6.651 \\
Difference AB-A & - & - & 0.265 \\
RET_AB_HIT96 & 6.677 & 6.374 & 6.830 \\
RET_A_HIT96 & 6.710 & 6.321 & 6.771 \\
Difference AB-A & -0.033 & 0.053 & 0.059 \\
\hline
\end{tabular}

Table 4. Correlation coefficients $\mathrm{r}\left(\mathrm{AB}-\mathrm{A}, \mathrm{AB}-\mathrm{A}_{-} v_{3}\right)$ and $\mathrm{r}\left(\mathrm{AB}-\mathrm{A}, \mathrm{A}_{-} v_{3}-\mathrm{A}\right)$ calculated between differences in retrieved ozone VMRs using microwindows from MIPAS band AB (RET_AB_MIPAS), band A between 730 and $800 \mathrm{~cm}^{-1}$ (RET_A_MIPAS) or band A_v 3 between 960 and $970 \mathrm{~cm}^{-1}$ (RET_A_v ${ }_{3}$ MIPAS), for different height ranges.

\begin{tabular}{lllll}
\hline Orbit & Date & $\begin{array}{l}\text { Height } \\
\text { range }[\mathrm{km}]\end{array}$ & $\mathrm{r}\left(\mathrm{AB}-\mathrm{A}, \mathrm{AB}-\mathrm{A}_{-} \nu_{3}\right)$ & $\mathrm{r}\left(\mathrm{AB}-\mathrm{A}, \mathrm{A}_{-} \nu_{3}-\mathrm{A}\right)$ \\
\hline 5852 & 13 April 2003 & $25-40$ & 0.072 & 0.523 \\
7274 & 22 July 2003 & $25-40$ & 0.066 & 0.450 \\
8597 & 22 Oct 2003 & $25-40$ & 0.063 & 0.501 \\
5852 & 13 Apri12003 & $20-50$ & 0.157 & 0.395 \\
7274 & 22 July 2003 & $20-50$ & 0.129 & 0.374 \\
8597 & 22 Oct 2003 & $20-50$ & 0.090 & 0.416 \\
\hline
\end{tabular}

\subsubsection{MIPAS gain calibration inconsistencies}

In order to assess if the observed discrepancies in ozone amounts can be attributed to gain calibration uncertainties between the MIPAS A and AB bands, another retrieval was performed using exclusively ozone lines of the $\nu_{3}$ band but located in MIPAS band A (RET_A_v $\nu_{3}$ MIPAS). These lines are situated between 960 and $970 \mathrm{~cm}^{-1}$ and are not contained in the microwindow set from band A applied above. Agreement of the retrieval result using these lines with the result obtained with the standard OM from band A would indicate a calibration problem. To check this, a correlation analysis was performed for the differences between the band $\mathrm{AB}$ results and the retrieval using the $960-970 \mathrm{~cm}^{-1}$ lines and the differences between the band $\mathrm{AB}$ and band $\mathrm{A}$ results (MWs from 730 to $798 \mathrm{~cm}^{-1}$ ). The result was that for each of the three orbits the differences between the MIPAS band AB retrievals and those using the $960-970 \mathrm{~cm}^{-1}$ region are only weakly correlated to the differences between the $\mathrm{AB}$ and $\mathrm{A}$ band retrievals, with correlation coefficients between $r=0.06$ and 0.16 for the altitude bands $25-40$ and $20-50 \mathrm{~km}$ (Table 4). This rules out gain calibration inconsistencies between the MIPAS bands to cause the retrieval discrepancies.

\subsubsection{Spectroscopic data}

In order to investigate if the observed discrepancies can be explained by spectroscopic inconsistencies in the MIPAS ozone database (Flaud et al., 2003), a similar correlation analysis was performed for the differences between band $\mathrm{AB}$ and $\mathrm{A}$ retrievals and the differences between the retrievals using the two band A line regions (results using the $730-798 \mathrm{~cm}^{-1}$ lines subtracted from results using the $960-$ $970 \mathrm{~cm}^{-1}$ lines). In this case, a correlation coefficient $\mathrm{r}=0.50$ was found for the altitude band $25-40 \mathrm{~km}$ of orbit 8597 (Table 4). Similar correlation coefficients, namely $\mathrm{r}=0.45$ and 
$\mathrm{r}=0.52$, were calculated for orbits 5852 and 7274 . The correlation coefficients calculated for the altitude band $20-50 \mathrm{~km}$ are $\mathrm{r}=0.40, \mathrm{r}=0.37$ and $\mathrm{r}=0.42$ for orbits 5852,7274 and 8597 , respectively. These rather high correlations suggest that inconsistencies between spectroscopic data in the ozone $v_{1} / \nu_{3}$ and $v_{2}$ bands are a major reason for discrepancies in related ozone retrievals. In the following we test, if such a bias can be explained by the spectroscopic uncertainties reported for the MIPAS ozone lines. After inclusion of non-LTE modelling, the orbit-averaged difference between band AB and A retrievals of orbit 8597 is about $4 \%(0.265 / 6.659$, Table 3$)$. This is in the range of the error given for the line intensities of the ozone fundamental lines used, which varies between 2 and $6 \%$ depending on the rotational quantum numbers (Flaud et al., 2003). Moreover, the additional error specified for the ozone line-widths is $5-10 \%$. To ensure the finding of a spectroscopic bias, the retrievals with band $\mathrm{A}$ and $\mathrm{AB}$ microwindows were repeated using ozone lines of the 1996 edition of the HITRAN database (Rothman et al., 1998). The retrievals with this spectroscopic dataset (RET_A_HIT96 and RET_AB_HIT96) resulted in constantly 3-4\% lower band $\mathrm{AB}$ ozone amounts over the whole stratosphere, but in up to $4 \%$ higher band A ozone amounts in the altitude region 28$37 \mathrm{~km}$. Thus, as net result smaller differences between band $\mathrm{AB}$ and $\mathrm{A}$ ozone amounts with positive sign above, but negative sign below $32 \mathrm{~km}$ were achieved (Fig. 9, bottom), suggesting a better consistency between the HITRAN96 lines used in MIPAS channels A and AB. Due to the changing sign, the orbit-averaged differences of this test are nearly zero in the altitude band $25-43 \mathrm{~km}$ (Table 3 ). Thereupon we tried to find out the reason for the larger deviations arising from the MIPAS ozone lines. The band AB difference resulting from use of the different line datasets is in good agreement with Flaud et al. (2003), who report intensity ratios of 1.044 and 1.035 between the HITRAN96 and the new calibrated MIPAS $v_{1}$ and $v_{3}$ lines, respectively. On the other hand, the difference within band A between the two line datasets is not explainable by an offset in line strengths only, since the intensities of the HITRAN96 $v_{2}$ lines are also higher by a factor of about 1.05 than those of the $v_{2}$ lines of the MIPAS database which would also lead to lower ozone VMRs. Further retrieval studies showed that this deviation results from the combination of the lower line strengths and of the generally larger (up to 15\%) air broadening coefficients of the MIPAS $\nu_{2}$ lines as compared to the respective parameters of the HITRAN96 dataset. The reason of the considerable influence of the line widths is that the peaks of the $v_{2}$ lines become saturated at this altitude region. In summary, we assign the major part, i.e. about $70 \%$, of the observed discrepancies to inconsistencies in spectroscopic data, and the remaining part to band dependent NLTE effects not taken into account in IMK retrievals (cf. Sect. 3.3.1).
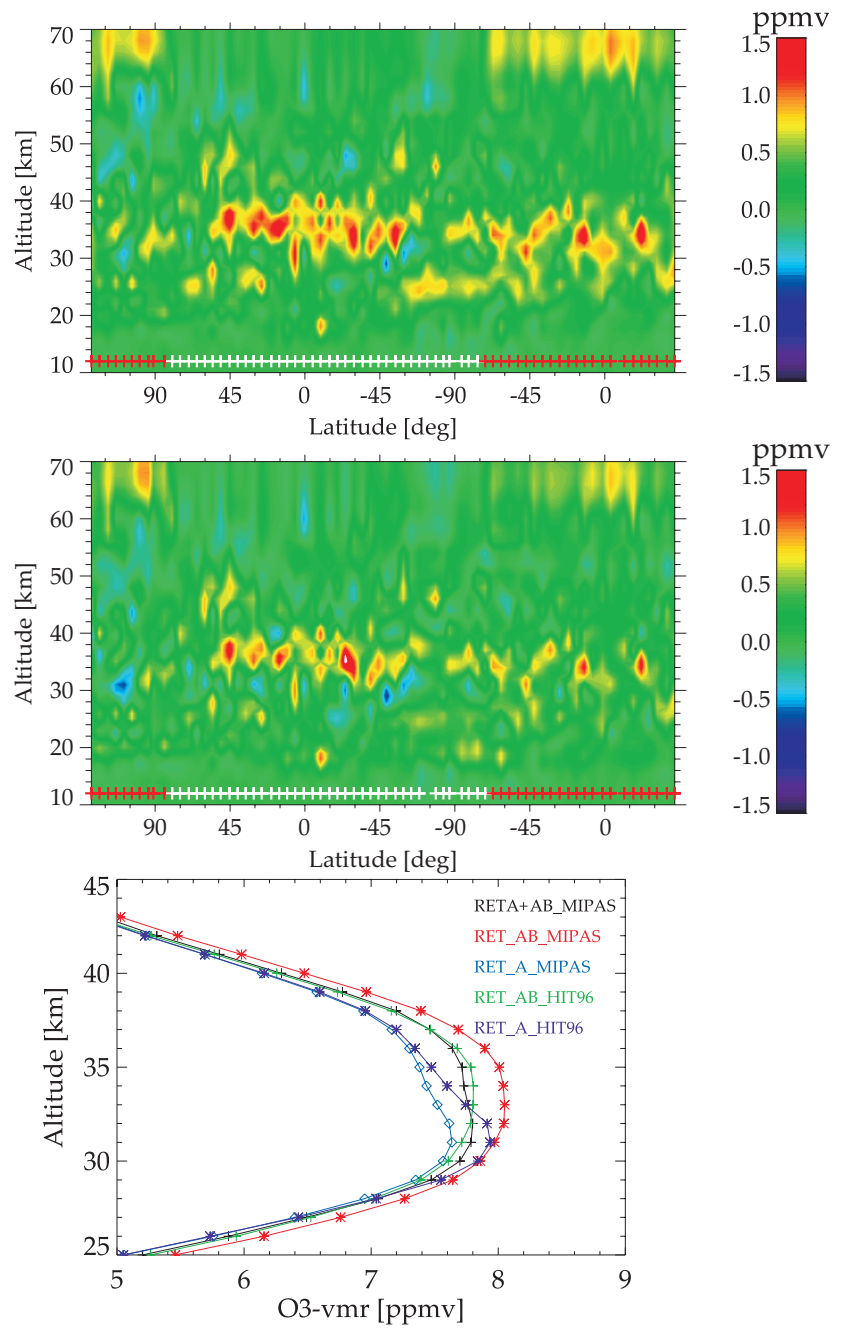

Fig. 9. Top: Difference between ozone amounts retrieved using occupation matrices restricted to MIPAS band AB (RET_AB_MIPAS) or A (RET_A_MIPAS), respectively, without modelling of nonLTE effects. Same meaning of plus signs as in Fig. 1. Middle: Same as (top) but retrieval with modelling of non-LTE effects (RET_AB_MIPAS_NLTE and RET_A_MIPAS_NLTE). Bottom: Orbit averaged ozone amounts resulting from the reference calculation (black), from the calculations using microwindows from MIPAS bands AB (red) or A (blue) only and MIPAS ozone line parameters, and from the calculation using microwindows from MIPAS bands AB (green) or A (purple) only and HITRAN96 ozone line parameters.

\subsection{Regularization}

Since the retrieval grid used at IMK has a finer height spacing than the vertical tangent height distance (cf. Sect. 2), a constraint has to be applied for the retrieval of trace gas profiles to avoid instabilities. The smoothing constraint chosen for trace gas retrievals at IMK is implemented as follows

$\mathbf{R}=\mathbf{B} \mathbf{L}^{T} \mathbf{L B}$, 

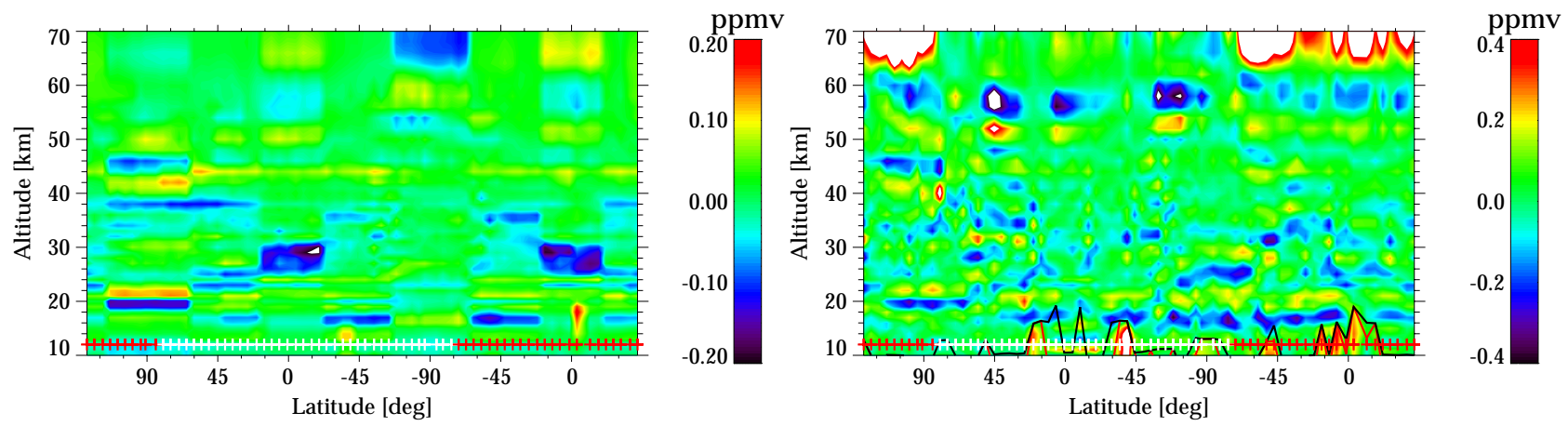

Fig. 10. Left: Difference between $\mathrm{O}_{3}$ retrieval with zero a-priori profile and reference retrieval (RET_A+AB_MIPAS). Right: Difference between retrieval with zero a-priori and reduced regularization strength and reference retrieval. Same meaning of plus signs as in Fig. 1.

where $\mathbf{R}$ (cf. Eq. 1) is the regularization matrix, $\mathbf{L}$ is Tikhonov's first-derivative operator (Steck, 2002) and B is a diagonal matrix containing the altitude-dependent regularization strength. This constraint tends to drive the retrieval towards the shape of the a-priori profile, if the measurement contains only little information on the target variable.

Until ozone data version V3o_O3_6 (V3o is ESA level 1 data versions 4.61-4.62, processed offline at DFD, O3_6 is IMK ozone retrieval setup 6) climatological ozone profiles were used as a-priori profiles. In order to avoid any inappropriate mapping of the a-priori profiles onto the result, from data version V3o_O3_7 on, all-zero a-priori profiles are used. However, climatological ozone profiles are further applied as first guess for the least-squares fit in order to save iterations. The differences between retrievals using all-zero or climatological a-priori profiles are below \pm 0.2$]$ ppmv (Fig. 10) and thus in the altitude region $20-45 \mathrm{~km}$ smaller than the total precision (cf. Fig. 2). Below 20 and above $50 \mathrm{~km}$ the deviations are of the same order or larger than the total precision.

The regularization strength originally defined for IMK ozone retrievals varied with altitude $\mathrm{z}$ approximately $\sim 1$ VMR(z) where VMR is the volume mixing ratio of a climatological profile, i.e. it was scaled such that real profile features are best possibly detected while instabilities triggered by measurement noise and other uncorrected measurement errors are suppressed. The appropriateness of the strength of the smoothing constraint was estimated from the height resolution or degrees of freedom of the retrieved profiles (Rodgers, 2000; Steck, 2002).

In operational data processing, the regularization strength, which was pre-calculated for a certain geolocation, is used for evaluation of all measurements along the whole orbit. This leads to a number of degrees of freedom $d_{r}$, defined as trace of the averaging kernel A (cf. Steck, 2002)

$d_{r}=\operatorname{tr}(\mathbf{A})$,

which is slightly varying with latitude because of change in atmospheric conditions. The ideal number of degrees of freedom attainable for a trace gas with significant signatures at each tangent altitude equals the number of tangent altitudes, which is 17 for a the standard MIPAS scan of high spectral resolution. For the reference retrieval (cf. Fig. 1) they vary between 11.7 at Arctic and 13.8 at Antarctic latitudes, which indicates that the constraint used until data version V3o_O3_6 is rather strong (Fig. 10, right). This slight over-regularization was neccessary, because in the first version of level-1B datasets produced from MIPAS measurements before 18 September, 2002, gain oscillations occured between spectra from subsequent tangent heights. In spectra produced after September 2002 and in all re-calibrated spectra this problem was largely reduced, which justifies weaker regularization.

For this purpose, we studied the effect of a constraint weakened by $33 \%$ between 20 and $50 \mathrm{~km}$ and considerably more in the altitude regions below 20 and above $50 \mathrm{~km}$, which resulted in 15-17 degrees of freedom for the reference orbit. This regularization might in some cases lead to oscillations or unrealistic gradients in the upper stratosphere in single profiles with little information content, but assures best possible detection of ozone signatures in the upper troposphere/lower stratosphere region and in the upper stratosphere. Combined use of a zero a-priori and the weaker constraint leads to differences to the standard retrieval, which are generally below $\pm 0.3 \mathrm{ppmv}$ in the altitude region $15-50 \mathrm{~km}$ (Fig. 10, right). The nighttime deviations above $60 \mathrm{~km}$ of up to 1 ppmv reflect a clearer detection of the tertiary nighttime ozone maximum. However, the absolute VMRs at these high altitudes have to be handled with some care because of possible NLTE-effects, which are not taken explicitely into account in IMK ozone retrieval (cf. Sect. 2). In summary, for the reasons given above, the newly defined regularization will be applied to ozone retrievals starting from version V3o_O3_7. 


\section{Data versions}

Figure 11 (top) shows the end-to-end differences between MIPAS ozone amounts obtained with the new baseline (V3o_O3_7) and with the reference baseline (V2_O3_2). As discussed in Sect. 3, these differences consist in continuum representation, the applied cloud-threshold, the a-priori profile used and in the regularization strength: In the reference retrieval an individual continuum profile was fitted for each microwindow. Further, a cloud-threshold of 1.8 and a climatological ozone a-priori profile were used. According to the new baseline, a common continuum profile is retrieved for adjacent microwindows within a $5 \mathrm{~cm}^{-1}$ spectral range, the cloud-threshold is increased to 4.0, the a-priori profile used is an all-zero profile, and the regularization strength is decreased by $33 \%$ in the region of the ozone maximum and even stronger at lower and higher altitudes. Apart from the height region $20-35 \mathrm{~km}$ at high southern latitudes, the deviations mainly result from the different constraints and are mostly lower than $\pm 0.3 \mathrm{ppmv}$ in the altitude range $15-50 \mathrm{~km}$. This is smaller than the total retrieval error between 25 and $45 \mathrm{~km}$ and of the order of the total precision at $35 \mathrm{~km}$. At higher and lower altitudes the total retrieval error is exceeded in several places.

The results of a preliminary intercomparison between ozone amounts measured by MIPAS (data version V2_O3_2) and HALOE during the period 30 October to 7 November 2003 are presented in Fig. 11 (bottom). The HALOE profiles taken into account are from the level 2-version 19 database of the British Atmospheric data Centre (BADC). They cover the altitude region from the cloud top up to about $90 \mathrm{~km}$ with a vertical resolution of $\sim 2 \mathrm{~km}$. The HALOE uncertainties are between $\sim 9 \%$ in the middle stratosphere and $20-25 \%$ in the lower stratosphere and mesosphere. The maximum differences allowed for the intercomparison of MIPAS and HALOE profiles were $\pm 5^{\circ}$ in latitude, $\pm 10^{\circ}$ in longitude and $\pm 12 \mathrm{~h}$ in time. More details about the methodology are given in Wang et al. (2005). The main differences occur at southern latitudes and consist of a negative band of up to -1 ppmv at $20 \mathrm{~km}$ and two positive bands of up to 1 ppmv between 26 an $34 \mathrm{~km}$ and around $40 \mathrm{~km}$ altitude. The differences at $20 \mathrm{~km}$ altitude are at least partly compensated by the new retrieval setup (Fig. 11, top), whereas the positive differences around $30 \mathrm{~km}$ are reduced above, but enhanced below $30 \mathrm{~km}$.

\section{Conclusions}

We have investigated the dependence of $\mathrm{O}_{3}$ retrievals from MIPAS spectra on modification of several processing parameters to better understand possible error sources and to define an updated processing baseline, which will be used for ozone retrievals beginning from data version V3o_O3_7. The resulting deviations from the reference retrieval (version V2_O3_2) were compared with the total retrieval error, which amounts
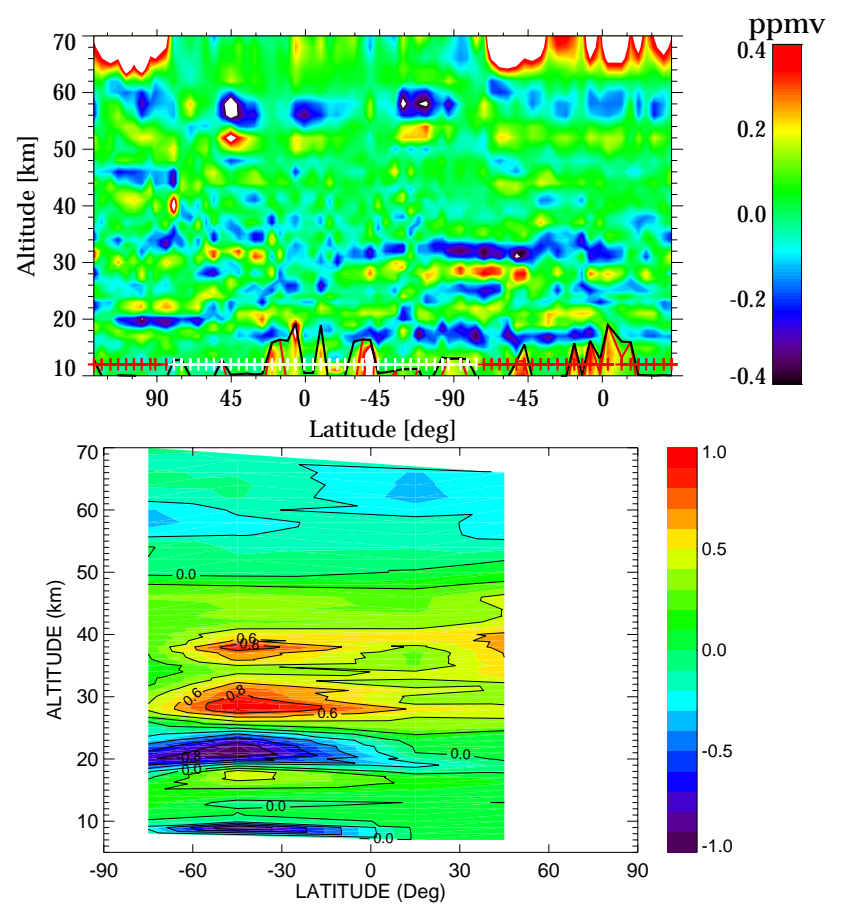

Fig. 11. Top: Difference between MIPAS ozone retrievals along orbit 8597 of 22 October 2003, using baselines V3o_O3_7 (new) and V2_O3_2 (old), respectively. The differences consist in continuum representation, in the applied cloud-threshold (4.0 or 1.8), the a-priori profile used (all-zero or climatological), and in the regularization strength. More details are given in Sect. 3. Same meaning of plus signs as in Fig. 1. Bottom: Differences (MIPAS-HALOE) between ozone amounts measured by MIPAS (data version V2_O3_2) and HALOE found in an intercomparison of the period 30 October to 7 November 2003. MIPAS data used are from the dayside part of the orbit only; because of the instrument's measurement mode, no HALOE data were available from north of $45^{\circ} \mathrm{N}$.

up to $0.65 \mathrm{ppmv}$ in polar regions and up to $1.2 \mathrm{ppmv}$ in the tropics, and with the random error, which amounts up to 0.2 ppmv.

It was found that the cloud clearing procedure applied so far (cloud-index 1.8) does not exclude moderately cloudcontaminated spectra. This can lead to additional retrieval errors of the order of the cloud-free total error up to $3 \mathrm{~km}$ above the cloud-layer. Therefore we decided to increase the cloudthreshold to the value of 4.0. Further, model calculations have shown, that assignment of the same background continuum radiance profile for adjacent microwindows within spectral intervals of $5 \mathrm{~cm}^{-1}$ is sufficient to represent the continuum emisssion of aerosols, clouds and gases. Applied on ozone retrievals, the deviations from the reference calcualation, where this simplification was not applied, were generally less than $0.2 \mathrm{ppmv}$. Thus, this approach, which also saves computation time, will be used in the new processing baseline. In addition, we investigated a possible bias between retrieval results obtained with microwindows from MIPAS 
bands A $\left(685-970 \mathrm{~cm}^{-1}\right)$ and $\mathrm{AB}\left(1020-1170 \mathrm{~cm}^{-1}\right)$, since microwindows from both bands are used in IMK ozone retrieval. Such a difference of up to 1 ppmv between band AB and band A results was indeed found. By inclusion of modelling of non-LTE effects in the retrieval, the difference could be reduced by about $30 \%$. However it turned out, that the main reason is obviously a spectroscopic bias between the ozone lines used in these two bands, i.e. the $v_{2}$ (band A) and $v_{1} / v_{3}$ (band AB) lines. This was found by correlation analysis as well as by use of another spectroscopic dataset. A bias in radiance calibration of the level-1B spectra from bands $\mathrm{A}$ and $\mathrm{AB}$ could largely be ruled out by correlation analysis and by inspection of broadband spectra.

Further, the $\mathrm{O}_{3}$ profiles retrieved using an all zero a-priori profile were only little different from the reference calculation with a climatological a-priori profile (deviations up to $\pm 0.2 \mathrm{ppmv}$ ). Thus we will apply a zero a-priori profile to future ozone retrievals to avoid any possible mapping of the structure of the a-priori profiles onto the result. Moreover, a reduced regularization strength, defined to improve the overall height resolution and especially the detectability of ozone signatures in the lower and upper stratosphere, was successfully tested and will be applied in future. An end-to-end comparison between the new and old retrieval baseline resulted in differences of up to $\pm 0.4 \mathrm{ppmv}$ in the altitude region 20 $60 \mathrm{~km}$. Further it was shown that the differences found in an initial validation study are reduced by application of the new baseline.

Acknowledgements. The authors like to thank the reviewers and J.-M. Flaud for helpful comments as well as ESA for giving access to MIPAS level-1 data. Meteorological analysis data have been provided by ECMWF. The IAA team has been partially supported by Spanish projects REN2001-3249/CLI and ESP2004-01556, and by EC FEDER funds.

Edited by: A. Richter

\section{References}

Biermann, U. M., Luo, B. P., and Peter, T.: Absorption spectra and optical constants of binary and ternary solutions of $\mathrm{H}_{2} \mathrm{SO}_{4}$, $\mathrm{HNO}_{3}$, and $\mathrm{H}_{2} \mathrm{O}$ in the mid infrared at atmospheric temperatures, J. Phys. Chem. (A), 104, 4, 783-793, 2000.

Clough, S.A.: The water vapor continuum and its role in remote sensing, in Optical Remote Sensing of the Atmosphere, vol. 2 of OSA Tech. Dig. Ser., 76-78, Optical Society of America, Washington, D.C., 1995.

Cousin, C., Le Doucen, R., Boulet, C., and Henry, A.: Temperature dependence of the absorption in the region beyond the $4.3-\mu \mathrm{m}$ band head of $\mathrm{CO}_{2} .2: \mathrm{N}_{2}$ and $\mathrm{O}_{2}$ broadening, Appl. Opt., 24(22), 3899-3907, 1985.

Deshler, T., Hervig, M. E., Hoffmann, D. J., Rosen, J. M., and Liley, J. B.: Thirty years of in situ stratospheric aerosol size distribution measurements from Laramie, Wyoming $\left(41^{\circ} \mathrm{N}\right)$, us- ing balloon-borne instruments, J. Geophys. Res., 108(D5), 4167, doi:10.1029/2002JD002514, 2003.

Echle, G., von Clarmann, T., Dudhia, A., Flaud, J.-M., Funke, B., Glatthor, N., Kerridge, B., López-Puertas, M., Martín-Torres, F. J., and Stiller, G. P.: Optimized spectral microwindows for data analysis of the Michelson Interferometer for Passive Atmospheric Sounding on the Environmental Satellite, Appl. Opt., 39(30), 5531-5540, 2000.

European Space Agency: Envisat, MIPAS An instrument for atmospheric chemistry and climate research, ESA Publications Division, ESTEC, P. O. Box 299, 2200 AG Noordwijk, The Netherlands, SP-1229.

Fischer, H. and Oelhaf, H.: Remote sensing of vertical profiles of atmospheric trace constituents with MIPAS limb-emission spectrometers, Appl. Opt., 35(16), 2787-2796, 1996.

Flaud, J.-M., Piccolo, C., Carli, B., Perrin, A., Coudert, L.H., Teffo, J.-L., and Brown, L.R.: Molecular line parameters for the MIPAS (Michelson Interferometer for Passive Atmospheric Sounding) experiment, Atmos. Oceanic Opt., 16, 3, 172-182, March, 2003.

Gil-López, S., von Clarmann, T., Funke, B., García-Comas, M., Glatthor, N., Grabowski, U., Höpfner, M., Kaufmann, M., Koukouli, M.E., López-Puertas, M., and Stiller, G.P.: Retrieval of stratospheric and mesospheric $\mathrm{O}_{3}$ from high resolution MIPAS spectra at 15 and $10 \mu \mathrm{m}$, Adv. Space Res., 36, 943-951, 2005.

Glatthor, N., von Clarmann, T., Fischer, H., Funke, B., Grabowski, U., Höpfner, M., Kellmann, S., Kiefer, M., Linden, A., Milz, M., Steck, T., Stiller, G. P., Mengistu Tsidu, G., and Wang, D.Y: Spaceborne $\mathrm{ClO}$ observations by the Michelson Interferometer for Passive Atmospheric Sounding (MIPAS) before and during the Antarctic major warming in September/October 2002, J. Geophys. Res., 109, D11307, doi:10.1029/2003JD004440, 2004.

Höpfner, M., von Clarmann, T., Fischer, H., Funke, B., Glatthor, N., Grabowski, U., Kellmann, S., Kiefer, M., Linden, A., Mengistu Tsidu, G., Milz, M., Steck, T., Stiller, G. P., and Wang, D.-Y: First spaceborne observations of Antarctic stratospheric $\mathrm{ClONO}_{2}$ recovery: Austral spring 2002, J. Geophys. Res., 109(D11), D11308, doi:10.1029/2004JD004609, 2004.

Höpfner, M., and Emde, C.: Comparison of single and multiple scattering approaches for the simulation of limb-emission observations in the mid-IR, J. Quant. Spectrosc. Radiat. Transfer, 91, 3, 275-285, doi:10.1016/j.jqsrt.2004.05.066, 2005.

Marsh, D., Smith, A., Brasseur, G., Kaufmann, M., and Grossmann, K.: The existence of a tertiary ozone maximum in the high-latitude middle mesosphere, Geophys. Res. Lett., 28, 45314534, 2001.

Mengistu Tsidu, G., von Clarmann, T., Stiller, G.P., Höpfner, M., Fischer, H., Funke, B., Glatthor, N., Grabowski, U., Kellmann, S., Kiefer, M., Linden, A., Mengistu Tsidu, G., Milz, M., Steck, T., and Wang, D.-Y.: Stratospheric $\mathrm{N}_{2} \mathrm{O}_{5}$ in the austral spring 2002 as retrieved from limb emission spectra recorded by the Michelson Interferometer for Passive Atmospheric Sounding (MIPAS), J. Geophys. Res., 109, D18301, doi:10.1029/2004JD004856, 2004.

Menoux, V., Le Doucen, R., and Boulet, C.: Line shape in the lowfrequency wing of self-broadened $\mathrm{CO}_{2}$ lines, Appl. Opt., 26, 3 , 554-562, 1987.

Menoux, V., Le Doucen, R., Boissoles, J., and Boulet, C.: Line shape in the low frequency wing of self- and $\mathrm{N}_{2}$-broadened $\nu_{3}$ $\mathrm{CO}_{2}$ lines: temperature dependence of the asymmetry, Appl. 
Opt., 30, 3, 281-286, 1991.

Nett, H., Perron, G., Sanchez, M., Burgess, A., and Mossner, P.: MIPAS inflight calibration and processor validation, in ENVISAT Calibration Review - Proc. of the European Workshop, 9-13 September 2002, ESTEC, Noordwijk, The Netherlands, CD-ROM, vol. SP-520, edited by H. Sawaya-Lacoste, ESA Publications Division, ESTEC, Postbus 299, 2200 AG Noordwijk, The Netherlands, 2002.

Rodgers, C. D.: Inverse Methods for Atmospheric Sounding: Theory and Practice, volume 2 of Series on Atmospheric, Oceanic and Planetary Physics, edited by: Taylor, F. W., World Scientific, 2000.

Rothman, L. S., Rinsland, C. P., Goldman, A., Massie, T., Edwards, D. P., Flaud, J.-M., Perrin, A., Camy-Peyret, C., Dana, V., Mandin J.-Y., Schroeder, J., McCann, A., Gamache, R. R., Wattson, R. B., Yoshino, K., Chance, K. V., Jucks K. W., Brown L. R., Nemtchinov, V., and Varanasi, P.: The HITRAN molecular spectroscopic database and HAWKS (HITRAN Atmospheric Workstation): 1996 Edition. J. Quant. Spectrosc. Radiat. Transfer, 60, 665-710, 1998.

Spang, R., Remedios, J. J., and Barkley, M. P.: Colour indices for the detection and differentiation of cloud types in infra-red limb emission spectra, Adv. Space Res., 33(7), 1041-1047, 2004.

Steck, T.: Methods for determining regularization for atmospheric retrieval problems, Appl. Opt., 41(9), 1788-1797, 2002.

Stiller, G. P. (Ed.): The Karlsruhe Optimized and Precise Radiative transfer Algorithm (KOPRA), Institut für Meteorologie und Klimaforschung, Forschungszentrum Karlsruhe GmbH, 2000.

Toon, O. B., Tolbert, M. A., Koehler, B. G., Middlebrook, A. M., and Jordan, J.: Infrared optical constants of $\mathrm{H}_{2} \mathrm{O}$ ice, amorphous nitric acid solutions, and nitric acid hydrates, J. Geophys. Res., 99(D12), 25 631-25 654, 1994.
Warren, S. G.: Optical constants of ice from the ultraviolet to the microwave, Appl. Opt., 23(8), 1206-1225, 1984.

von Clarmann, T. and Echle, G.: Selection of optimized microwindows for atmospheric spectroscopy, Appl. Opt., 37(33), 76617669, 1998.

von Clarmann, T., Ceccherini, S., Doicu, A., Dudhia, A., Funke, B., Grabowski, U., Hilgers, S., Jay, V., Linden, A., LópezPuertas, M., Martín-Torres, F.-J., Payne, V., Reburn, J., Ridolfi, M., Schreier, F., Schwarz, G., Siddans, R., and Steck, T.: A blind test retrieval experiment for infrared limb emission spectrometry, J. Geophys. Res., 108,(D23), 4746, doi:10.1029/2003JD003835, 2003a.

von Clarmann, T., Fischer, H., Funke, B., Glatthor, N., Grabowski, U., Höpfner, M., Kellmann, S., Kiefer, M., Linden, A., Mengistu Tsidu, G., Milz, M., Steck, T., Stiller, G. P., Wang, D.-Y., Gil-López, S., and López-Puertas, M.: Retrieval of temperature and tangent altitude pointing from limb emission spectra recorded from space by the michelson interferometer for passive atmospheric sounding (MIPAS), J. Geophys. Res., 108(D23), doi:10.1029/2003JD003602, 2003b.

Wang, D. Y., Stiller, G. P., von Clarmann, T., Fischer, H., Glatthor, N., Grabowski, U., Höpfner, M., Kellmann, S., Kiefer, M., Linden, A., Mengistu Tsidu, G., Milz, M., Steck, T., Wohnsiedler, S., López-Puertas, M., Funke, B., Gil-López, S., Kaufmann, M., Koukouli, M. L., Murtagh, D., Lautié, N., Jiménez, C., Jones, A., Eriksson, P., Urban, J., de La Noë, J., Le Flochmoën, É., Dupuy, É., Ricaud, P., Olberg, M., Frisk, U., Russell III, J., and Remsberg, E.: Comparison of MIPAS/ENVISAT ozone profiles with SMR/ODIN and HALOE/UARS observations, Adv. Sp. Res., 36, 927-931, 2005. 